\title{
An intelligent self-improving control strategy with a variable structure and time-varying parameters for water turbine governor
}

\author{
O.P. Malik, G.S. Hope \\ The University of Calgary \\ (Alberta, Canada) \\ Luqing Ye, Shouping Wei, Haibo Xu \\ Huazhong University of Science and Technology \\ (Wuhan, China)
}

\begin{abstract}
Speed governor provides basic control in hydro power stations to ensure the reliability and the quality of electrical energy. In recent years, along with the development of the modern control theory and computer-based technology, much research concerning the control and microcomputerbased implementation has been done for water turbine governor and voltage regulator [1]-[7].
\end{abstract}

One of the more interesting control strategies is the adaptive control. The foundations of Self-Tuning Regulator (STR) and Model-Reference Adaptive System (MRAS) were laid in references $[8]-[10]$. Water turbine governing systems have peculiar characteristic that the dynamic process is relatively slow, but the variation of the plant parameters is relatively fast. Therefore, the parameters of the plant vary during the dynamic process. This makes the existent STR or MRAS approaches difficult to apply directly.

The variable structure control (VSC) $[11,12]$ is an attractive alternative. However for practical implementation, especially on complex systems e.g. non-linear, non-minimum phase, time-varying systems, a lot of problems must be solved. Moreover, the plant structure is considered as constant in the existing VSC theory.

Artificial intelligence is one of the most active branches in the control area. Its main idea is to make the system an intelligent machinery that can accumulate knowledge and experience and have self-learning and self-improving capability.

On the basis of the analysis of speed governing system, it is proposed to combine ideas from artificial intelligence, adaptive control and VSC in a new control strategy: Intelligent Self-Improving Control (ISIC) with Both Variable Structure and Parameters. The proposed control strategy is applied to the water-turbine governing system. The peculiarities of the water turbine system are analyzed and then a general description of the proposed system is given. The plant structure detection and parameter identification methods are discussed in order to determine the control strategy. The adaptive selection of control structure is discussed. The optimization of control parameters and the knowledge bank are also described.

\section{Analysis of plant and system}

A linear model of water-turbine governing system for a certain operating point is given in Appendix I. In general, both the structure and the parameters of the water turbine governing system are variable.

Stratégie de commande intelligente et auto-adaptative à structure et paramètres variables pour le régulateur de turbines hydrauliques.

L'article propose une stratégie de commande auto-adaptative à structure et paramètres variables dans le temps. Cette stratégie a une capacité d'apprentissage et d'auto-amélioration. Une banque de connaissances accumule les meilleures expériences en cours d'exploitation pour améliorer le régulateur avec son utilisation. En employant des inférences et une analyse logique, la banque de connaissances modifie la structure de commande et les paramètres de régulation suivant les conditions d'exploitation. En conséquence, cette stratégie est dite intelligente. La stratégie de commande proposée est appliquée au régulateur de turbines hydrauliques. 


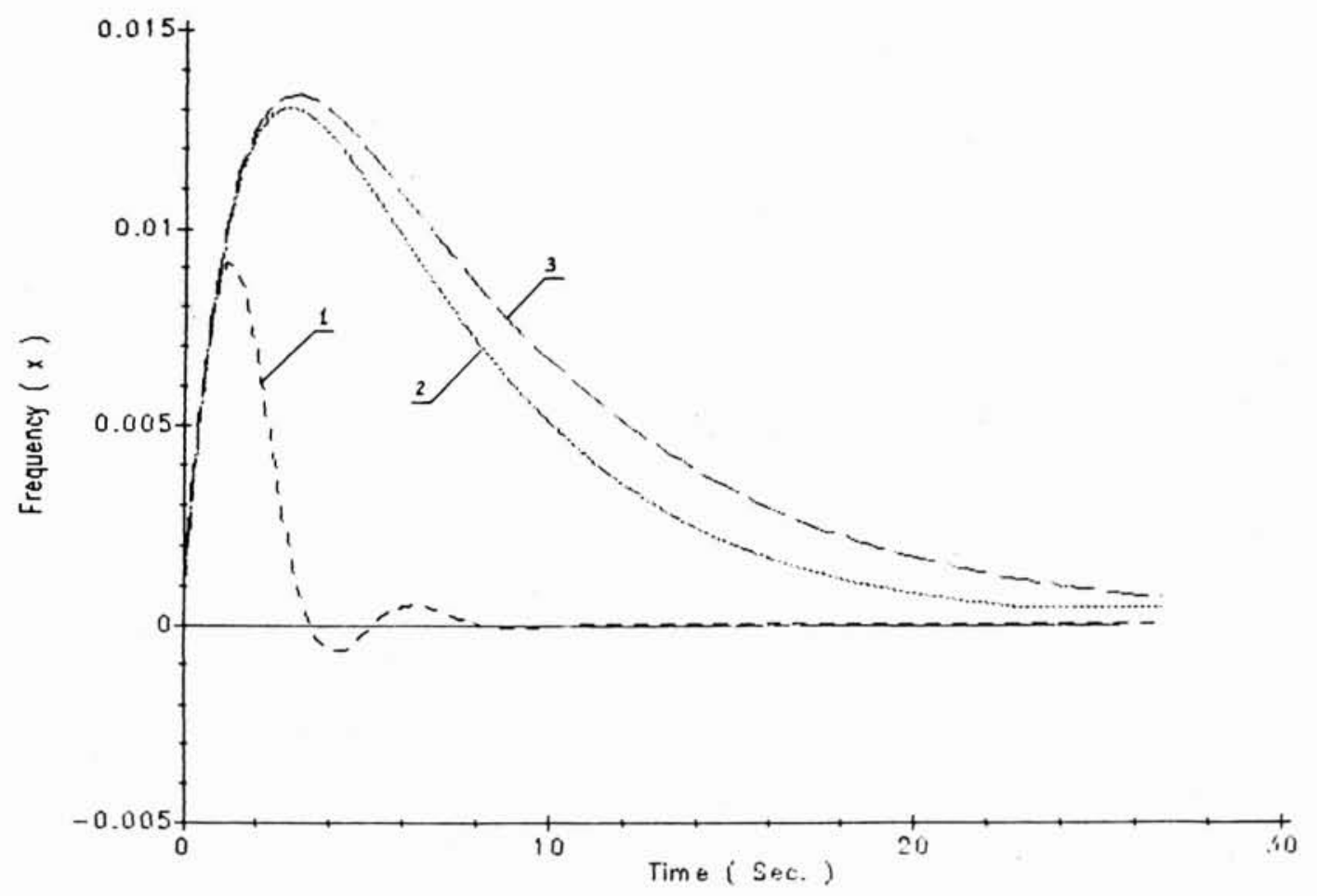

1. Frequency response to a $10 \%$ step change in load.

There are many different structures for water turbine governing system. From the point of view of connection with the network, there are no-load, operation in an isolated system, connection with a large interconnected network. As for control mode, there are frequency regulation, frequency and gate opening tracking (with set point), sequential control (start-up and shut-down). As for the penstock, while the gate is open, the water hammer effect has an influence on turbine behaviour. While the gate is closed, although the water hammer still exists in the penstock, it has no influence on the turbine. Moreover, the system contains saturation and deadband. Obviously, different control structures are necessary for various plant structures.

The plant parameters are also variable. For example, the transmission coefficients of turbine $e_{q y}, e_{q h}, e_{q x}, e_{y}, e_{h}$, and $e_{x}$ vary with water head and gate opening; $T_{b}$ and $e_{b}$ vary with load components and character (see Appendix I). Thus, it is reasonable to modify the control parameters or even the control structure relative to the variable plant parameters.

\section{Studies on Variable Structure}

The plant model, Appendix $I$, has the following parameters for a certain operating condition :

$$
\begin{aligned}
T_{w} & =1.27 \mathrm{~s} & T_{r} & =0.15 \mathrm{~s} & \left(T_{a}+T_{b}\right) & =9.06 \mathrm{~s} \\
e_{x} & =-0.1281 & e_{y} & =1.0669 & e_{h} & =0.5914 \\
e_{q x} & =-0.2002 & e_{q y} & =0.9333 & e_{q h} & =0.3789
\end{aligned}
$$

Using a PID or PI control law, tests were performed for three disturbances : $10 \%$ step load disturbance (1), $1 \%$ step change in frequency set point (2) and $8 \%$ step change in frequency set point (3).

For each disturbance, the corresponding regulator parameters were optimized.

Results of three studies for a $10 \%$ step load disturbance are given in table I and figure 1 . The curves in figure 1 correspond to the numbers in table $I$, and similarly for figures 2,3 and table II. The regulator parameters used in study No. 1 are optimal for a $10 \%$ step load disturbance. The parameters used in studies 2 and 3 are optimal for a step change in frequency set point of $1 \%$ and $8 \%$ respectively.

\begin{tabular}{|c|c|c|c|c|c}
\hline \multicolumn{4}{c}{ Table I. - 10\% step load disturbance. } \\
\hline \multirow{2}{*}{$\begin{array}{c}\text { Study } \\
\text { No. }\end{array}$} & \multicolumn{3}{|c}{$\begin{array}{c}\text { Regulator } \\
\text { parameters }\end{array}$} & \multicolumn{3}{c}{ Index } \\
\cline { 2 - 6 } & $K_{p}$ & $K_{i}$ & $K_{d}$ & $\begin{array}{c}\text { max. } \\
\text { error }\end{array}$ & $\begin{array}{c}\text { settling } \\
\text { time (s) }\end{array}$ \\
\hline 1 & 10.0 & 5.0 & 0.0 & 0.009 & 2.96 \\
\hline 2 & 4.4 & 0.8 & 2.0 & 0.013 & 15.16 \\
\hline 3 & 4.32 & 0.64 & 2.0 & 0.013 & 18.96 \\
\hline
\end{tabular}




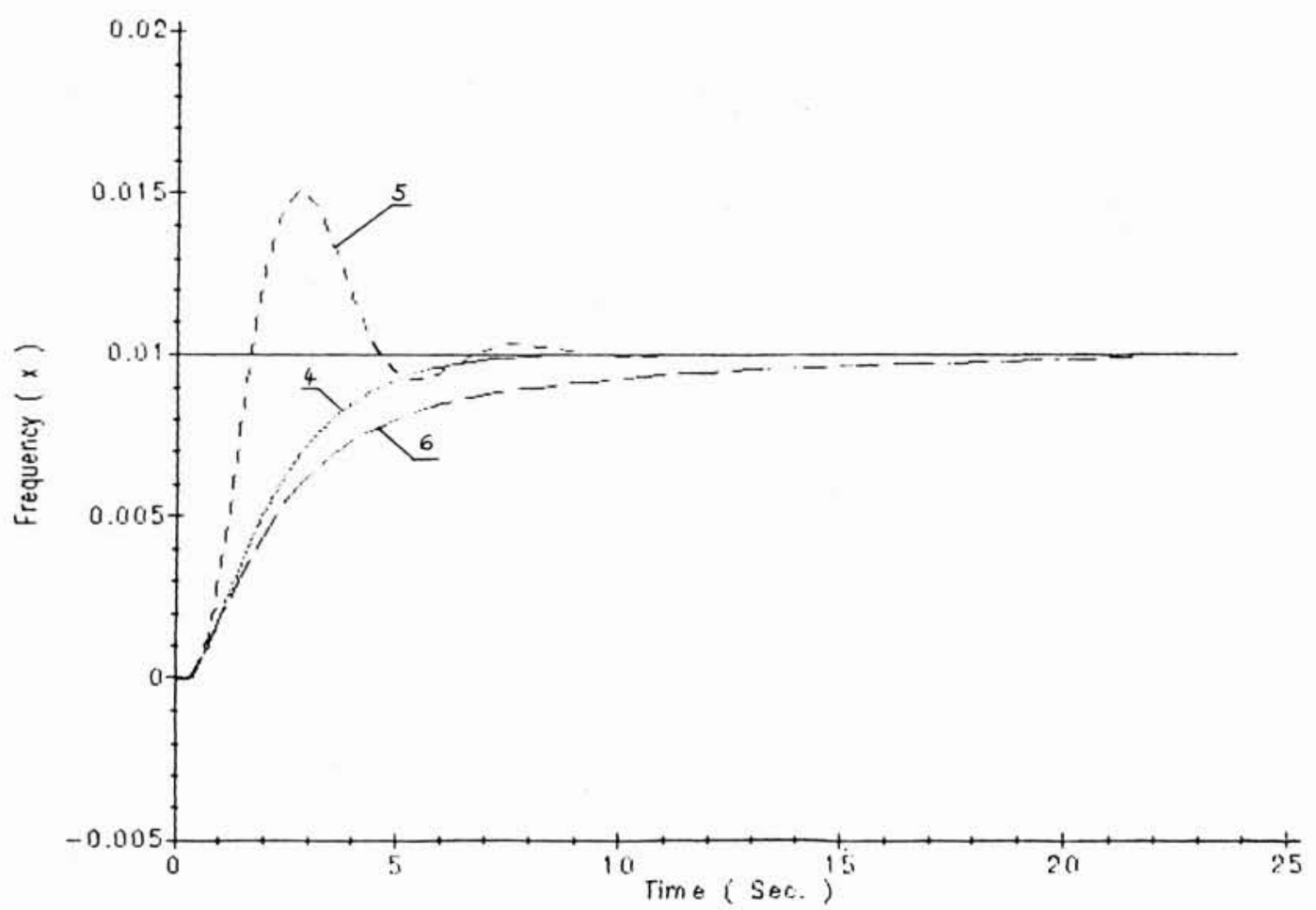

2. Response to a $1 \%$ step change in frequency set point.

Results for a $1 \%$ step change in frequency set point are given by studies 4-6 in Table II and figure 2. The regulator parameters for study No. 4 are optimal for this case, whereas the parameters in studies 5 and 6 are optimal for $10 \%$ step load disturbance and $8 \%$ step change in frequency set point respectively.

Results of studies 7-9 for an $8 \%$ step change in frequency set point are given in Table II and figure 3 . The regulator parameters for study 7 are optimal for this condition, whereas the parameters for studies 8 and 9 are optimal for a $1 \%$ step change in frequency set point and step change in load.

The above results show that for each mode of disturbance, there is a corresponding set of optimal parameters that gives good dynamic response. However, when one set of optimal parameters is applied to another mode of disturbance, the dynamic response degenerates and may even go unstable. A general conclusion is that various conditions require appropriate control structure and control parameters.

\section{Study of Variable Parameters}

The plant parameters vary with head, gate opening and connection with the network.

Parameters for two operating points are given in Table III. Other parameters are the same as in the preceding section.

Results for a $10 \%$ step change in load for operating point 1 , studies 10 and 11 , and operating point 2 , studies 12 and 13, are given in Table $I V$. The regulator parameters used

\begin{tabular}{|c|c|c|c|c|c|}
\hline \multicolumn{5}{|c|}{ Table II. - Step change in frequency set point. } \\
\hline $\begin{array}{c}\text { Study } \\
\text { No. }\end{array}$ & \multicolumn{3}{|c|}{$\begin{array}{c}\text { Regulator } \\
\text { Parameters }\end{array}$} & \multicolumn{2}{c|}{ Index } \\
\cline { 2 - 6 } & $K_{p}$ & $K_{i}$ & $K_{d}$ & $\begin{array}{c}\text { over- } \\
\text { shoot }\end{array}$ & $\begin{array}{c}\text { settling } \\
\text { time }(\mathrm{s})\end{array}$ \\
\hline 4 & 4.4 & 0.8 & 2.0 & 0.000 & 6.56 \\
\hline 5 & 10.0 & 5.0 & 0.0 & 0.005 & 8.4 \\
\hline 6 & 4.32 & 0.64 & 2.0 & 0.000 & 17.8 \\
\hline 7 & 4.32 & 0.64 & 2.0 & 0.001 & 6.4 \\
\hline 8 & 4.4 & 0.8 & 2.0 & 0.005 & 15.6 \\
\hline 9 & 10.0 & 5.0 & 0.0 & \multicolumn{3}{c|}{ unstable } \\
\hline
\end{tabular}

Table III. - Plant Parameters for two operating points.

\begin{tabular}{|c|c|c|c|c|c|c|c|c|}
\hline $\begin{array}{c}\text { Operat- } \\
\text { ing } \\
\text { Point }\end{array}$ & $\begin{array}{c}\text { Head } \\
(\mathrm{m})\end{array}$ & $\begin{array}{c}\text { Gate } \\
\text { Open- } \\
\text { ing }\end{array}$ & $e_{y}$ & $e_{h}$ & $e_{x}$ & $e_{q y}$ & $e_{q h}$ & $e_{q x}$ \\
\hline 1 & 52 & 22 & 0.9125 & 0.3558 & -0.0990 & 0.8025 & 1.0328 & -0.9023 \\
\hline 2 & 54 & 28 & 0.7566 & 0.4628 & -0.1617 & 0.9553 & 1.4465 & -1.3357 \\
\hline
\end{tabular}




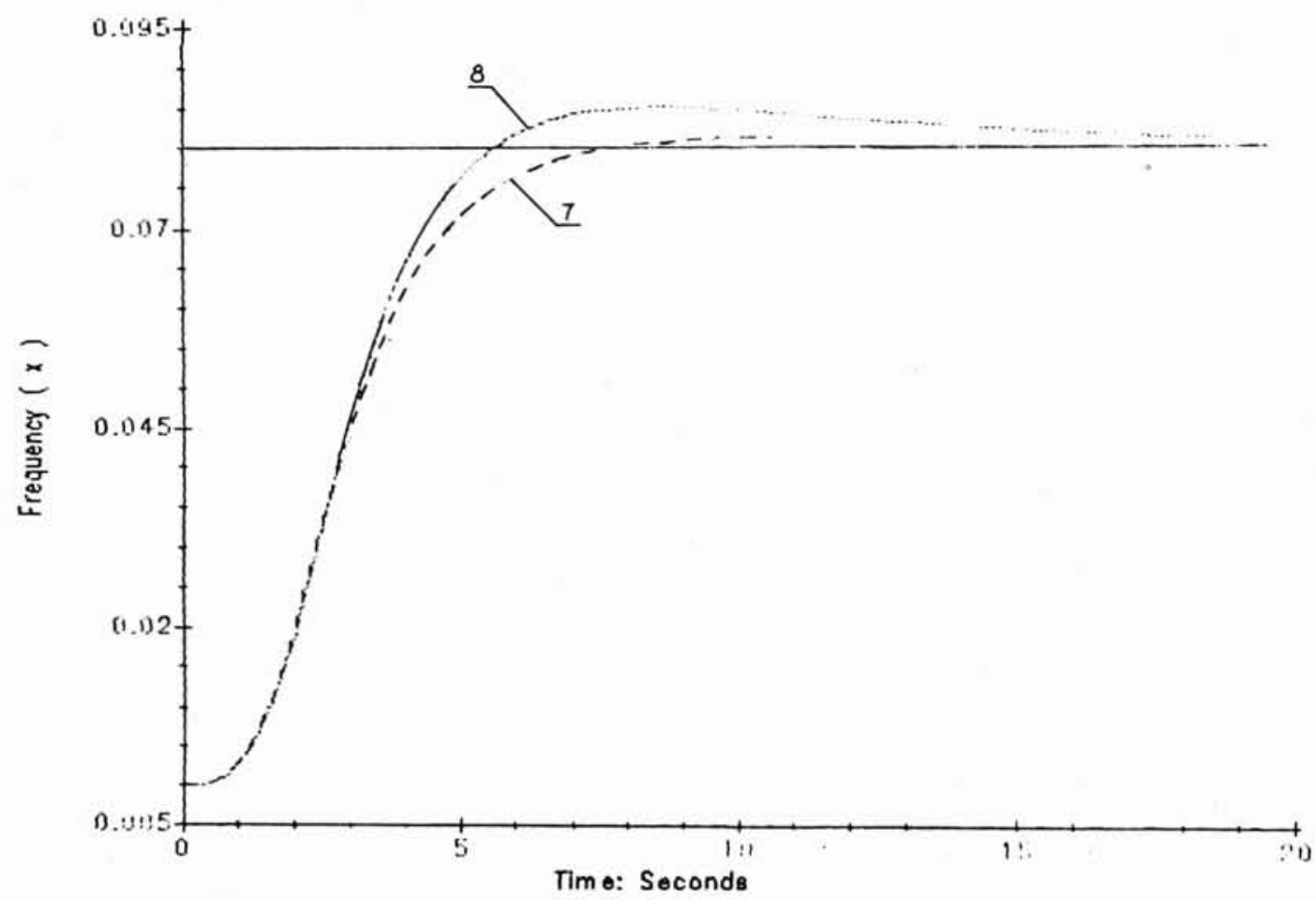

3. Response to a $8 \%$ step change in frequency set point.

in study 10 are optimal for this case (operating point 1), whereas the parameters used in study 11 are optimal for operating point 2 .

For operating point 2 , the regulator parameters used in study 12 are optimal in this case, whereas the parameters used in study 13 are optimal for operating point 1 .

\section{Analysis}

An analysis of the studies described above shows the following :

- The structure of the control system is different for the load disturbance and the frequency set point disturbance. Although the poles are the same, the zeros are different for the two cases. For the frequency set-point disturbance, there is a zero in the positive half s-plane and this is a tracking problem. For the load disturbance, there is no zero in the positive half s-plane and this is a regulation problem. Therefore, the control structure must be different for the two cases. The above studies also show that the PID law is necessary for the frequency set point disturbance, but that the PI law is more suitable for the load disturbance.

- For the same mode of disturbance, but with different disturbance values, the characteristics of the control system are also different. For example, for $1 \%$ frequency set point disturbance, the system can be rationally considered as linear; but with $8 \%$ frequency set point disturbance, the system is non-linear, and the control enters a saturation zone. Therefore, the regulator parameters and even the control structure must be variable.

- For various operating points, because of different plant parameters, the regulator parameters must be variable.

The above studies and analysis is only for a few representative cases. For the water turbine governing system, there are numerous regimes to be distinguished. Therefore, different control structures and parameters are necessary.

\begin{tabular}{|c|c|c|c|c|c}
\hline \multicolumn{5}{|c}{ Table IV. - 10\% step change in load. } \\
\hline \multirow{2}{*}{$\begin{array}{c}\text { Study } \\
\text { No. }\end{array}$} & \multicolumn{3}{|c}{$\begin{array}{c}\text { Regulator } \\
\text { Parameters }\end{array}$} & \multicolumn{2}{c}{ Index } \\
\cline { 2 - 6 } & $K_{p}$ & $K_{i}$ & $K_{d}$ & $\begin{array}{c}\text { Max } \\
\text { error }\end{array}$ & $\begin{array}{c}\text { Settling } \\
\text { time (s) }\end{array}$ \\
\hline 10 & 9.10 & 3.68 & 4.02 & 0.0212 & 3.00 \\
\hline 11 & 8.75 & 3.38 & 3.45 & 0.0210 & 3.40 \\
\hline 12 & 8.75 & 3.38 & 3.45 & 0.0183 & 3.12 \\
\hline 13 & 9.10 & 3.68 & 4.02 & 0.0190 & 4.44 \\
\hline
\end{tabular}




\section{General description of the control strategy}

Based on the analysis in the preceding section, an intelligent self-improving control strategy with both variable structure and parameters is developed. Its overall block diagram is shown in figure 4 . Besides the plant, the system contains three blocks : Detection and Identification, Knowledge Bank, and Controller. This system can be realized with a multimicroprocessor configuration.

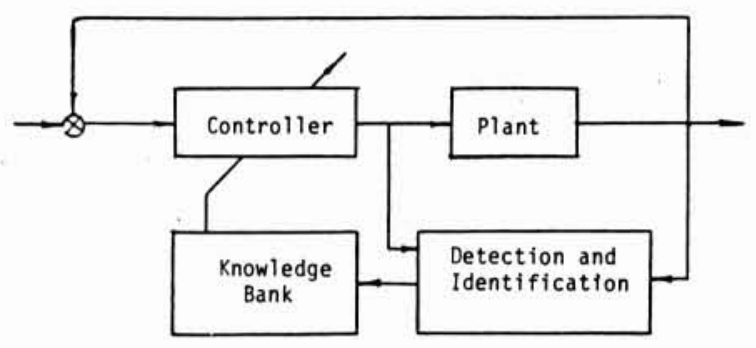

4. Overall control system.

The controller is multistructural and has variable parameters. Its general configuration is shown in figure 5. There are a lot of control strategies relative to different operating conditions. For each control strategy, the controller parameters are variable. The modification of both structures and parameters is directed by the knowledge bank.

\section{Detection and identification}

The role of this block is to detect and identify the plant structure and parameters as well as the system performance. It acquires all necessary information from the system to perform its functions and then sends the processed information to the knowledge bank. This block contains three branches as given below.

\section{Plant Structure Detection}

The plant structure is one of the main items necessary to select the control structure. The function of this branch is to acquire all necessary information and then recognize the plant structure.

\section{Detection of Type of Network}

Plant structure of the generator is different operating under various conditions, e.g., large network or isolated system. The turbine-generator dynamic equation that takes account of the load characteristics is given in equation (21), Appendix $I$. Under no-load and isolated conditions, $T_{b}=0$ and $e_{b}=0$. Depending upon the generator being connected to a large interconnected system or to an isolated system, $T_{b}$ and $e_{b}$ have different values. Obviously, the generator undertakes different functions under various conditions.

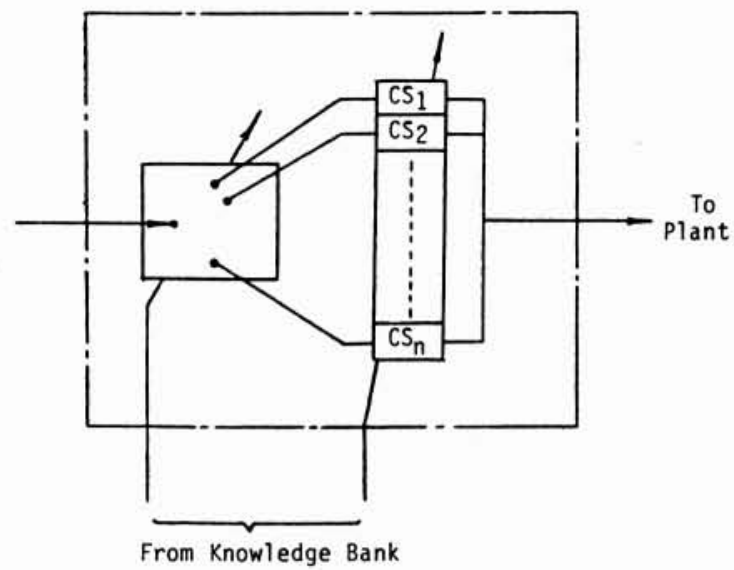

5. Configuration of controller.

Theoretically, $\left(T_{a}+T_{b}\right)$ and $e_{b}$ can be identified using equation (21), but because the network is too complex and interactive, this approach is almost not realizable. A practical approach is proposed below :

Defining $\sigma_{x}$ as the frequency variance of the generator, the following criterion can be adopted :

$$
\begin{array}{ll}
\sigma_{x}<\delta & \text { for large network } \\
\sigma_{x}>\delta & \text { for isolated system }
\end{array}
$$

where $\delta$ can be defined according to some specific condition.

The variance $\sigma_{x}$ for a time period of $N$ sampling periods, can be calculated with the following equation :

$$
\sigma_{x}=\left(\frac{1}{N} \sum_{j=1}^{N} x_{j}^{2}\right)^{1 / 2}
$$

\section{State Detection}

Two state (0-1) detection can get the following information : generator breaker position (on or off, it means if the unit is connected with the network), generator current (zero or non-zero, it means no-load or loaded), gate opening (zero or non-zero, it indicates if the water hammer has influence on the turbine), start-up command, shutdown command, frequency set point command, gate opening set-point command, opening limit command, generation/compensation switching command, etc.

The results of state detection can be expressed with a hexadecimal variable $I$. Each place represents a state. Different values of $I$ represent different plant structure.

Using this approach, the plant structure can be recognized.

\section{Parameter Identification}

Parameter identification is necessary because the plant parameters are different for various operating points and probably time-varying. However, in the proposed control strategy, the results of the plant parameter identification are not directly used to determine the control parameters in each 
sampling period. The main role of this function is to improve and renew the control parameters in the knowledge bank. In other words, it provides some information for self-improvement.

The block diagram for identification is shown in figure 6 .

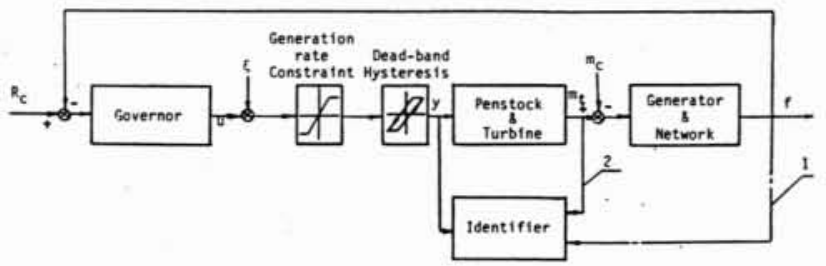

6. System block diagram for identification.

Conventionally, the penstock, turbine and generator are included in the identification loop, with $u$ as input, $x$ as output (with line 1 , but without line 2), and $\xi$ as the excitation noise signal. The generation rate constraint and the dead-band exist in the servomechanism, and are to be taken into account. Moreover, it is impossible to inject the noise signal to the mechanical stroke $y$. Therefore it is added at the regulator output.

According to the model given in the Appendix, the discrete model of the plant can be expressed as follows:

$$
\begin{aligned}
X(k+1)=-\sum_{i=1}^{4} a_{i} X(k- & i+1)+ \\
& +\sum_{j=1}^{4} b_{j} U(k-j+1)+e(k)
\end{aligned}
$$

where, $a_{i}(i=1-4)$ and $b_{j}(j=1-4)$ are discrete plant parameters, and $e(k)$ is the noise.

Using the RLS identification algorithm [13], and taking the excitation signal as zero mean Gaussian noise with variance $s=0.02$, the identification parameters are given in Table $\mathrm{V}$.

Take a disturbance shown below:

$$
e(t)=\sum_{i=1}^{3} S_{i} \operatorname{Sin}\left(\frac{2 \pi}{T_{i}} t\right)+\rho
$$

where $S_{i}=0.002(i=1,2,3), T_{i}=0.5,1.0,2.0, \rho$ is a white noise with the variance $\sigma_{\rho}=0.002$. The results of identification between $u$ and $x$ given in Table $\mathrm{V}$ show that even after one hundred steps, the identified parameters are far from the true parameters.

To overcome this problem, it was decided to identify the parameters of the penstock and the turbine only. This is justified because the parameters of the turbine and penstock vary a lot, but the time constant of the generator is comparatively constant and known. The identification model is now expressed as :

$$
\begin{aligned}
m_{t}(k+1)=-\sum_{i=1}^{3} a_{i} m_{t}(k- & i+1)+ \\
& +\sum_{j=1}^{3} b_{j} u(k-j+1)+e(k)
\end{aligned}
$$

Using RLS identification algorithm, the results are also shown in Table V. The exciting signal and the noise are the same as before. The parameters shown in Table $\mathrm{V}$ are for the full system. They are obtained from the identified parameters of penstock/turbine and the known parameters of generator/network.

It can be seen from Table $V$ that the proposed identification approach converges much faster and the errors between the real parameters and identified parameters are small. Therefore, this approach is feasible for water turbine governing system.

\section{Detection of Dynamic Performance}

For all dynamic processes, the performance can be identified with the following indices:

- Time-domain indices: the time-domain indices such as overshoot $M_{p}$ and settling time $T_{s}$ are largely used in engineering. For example, the index can be expressed as :

$$
J_{t}=\alpha M_{p}+\beta T_{s}
$$

where $\alpha$ and $\beta$ are the weighting coefficients.

- Statistical index : defining $\sigma_{x}$ and $\sigma_{u}$ as variance of frequency and control respectively, the statistical index can be defined as:

$$
J_{s}=\sigma_{x} / \sigma_{u} .
$$

\section{Knowledge bank}

The knowledge bank is the brain and heart of the control strategy proposed. With the help of its logical and inferential capability, control intelligence and self-improvement would be achieved. The configuration of the knowledge bank is shown in figure 7. Its information resource is the "Detection and Identification "block in figure 4 , and its output is sent to the controller.

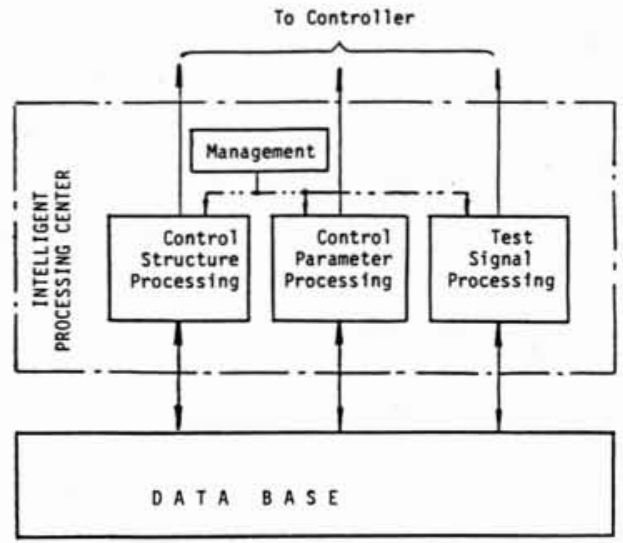

7. Configuration of knowledge bank. 
Table V. - Identification Results.

\begin{tabular}{|c|c|c|c|c|c|c|c|c|c|}
\hline Parameters & $a 1$ & $a 2$ & $a 3$ & $a 4$ & $b 1 \times 10^{-3}$ & $b 2 \times 10^{-3}$ & $b 3 \times 10^{-3}$ & $b 4 \times 10^{-3}$ & Steps \\
\hline True values & -2.4027 & 2.7069 & -2.0722 & 0.7735 & -1.042 & 2.06 & -2.459 & -1.951 & \\
\hline Identification between $u$ and $x$ & -0.6092 & -0.3541 & -0.1294 & 0.08732 & -1.576 & 0.316 & -1.088 & -2.657 & 100 \\
\hline Identification between $u$ and $m_{t}$ & -2.3774 & 2.6052 & -2.0209 & 0.7372 & -1.054 & 2.217 & -2.576 & -2.015 & 20 \\
\hline
\end{tabular}

The knowledge bank has two main parts as shown in figure 7. Data base stores all necessary information including control structure, control parameters, operating range, indices, test signal and identified plant structure and parameters. The contents of the data base are dynamic and updated under the direction of Intelligent Processing Center.

\section{Data Base (DB)}

The data base contains three branches as shown in figure 8 : Control, Identification and Test signal. All three branches communicate with each other.

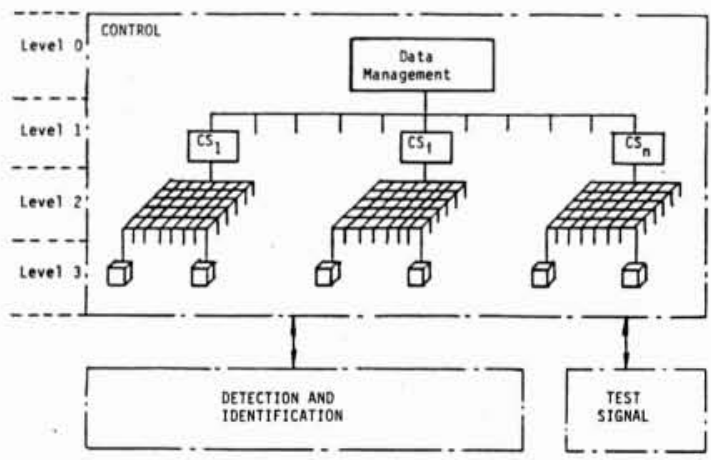

8. Outline of the data base.

The control and identification branches have a hierarchical structure. For example, the control branch contains four levels : Level 0 is " data management "; Level 1 is " control structure "; Level 2 is « operating range "; Level 3 is " control parameters and index $»$. The configuration of the identification branch is similar. The « test signal $"$ branch contains all necessary signals : white noise, step change, etc.

The data base is dynamic. On the one hand, the appropriate structure and parameters are sent to the controller under the direction of the intelligent processing center; on the other hand, the contents of the data base are renewed and improved.

\section{Intelligent Processing Center (IPC)}

This is a key part to realize the intelligent control. There are a number of rules concerning analysis. logical judgment, inference and decision. It consists of four units discussed below.

\section{Control Structure Processing}

The control structure can be adaptively selected with a three step hierarchy.

- On the basis of the Plant Structure :

The control structure firstly depends on the plant structure. On the basis of plant structure detection, possible control structure would be selected.

- On the basis of the plant parameters:

The plant parameters (e.g. $e_{q y}, e_{q h}, e_{q x}, e_{y}, e_{h}, e_{x}$ ) of water turbine governing system are variable mainly with the head and gate opening. The control structure may be different for different operating points.

- On the basis of the State and Output :

Taking the PID regulator as an example, under various output conditions and/or state error, the control strategy can be different: $\mathrm{P}$ or PI, or PD, or PID.

Synthesizing the three above-mentioned steps, appropriate rule for control structure selection can be designed. On the basis of the detection and identification, different structures are tested and judged. After performance appraisal, always the best structure is selected. In other words, the rules and control structure are continuously self-improved during operation. Therefore, the control structure ameliorates.

\section{Control Parameter Processing}

The control parameters are stored in the data base at control level 3 in figure 8 . One of the strengths of the control strategy under study is that the control parameters are selfimproved. The initial values of control parameters relative to the corresponding structure and the indices are precalculated by off-line simulation and prestored in the data base. The one-line parameter optimization is processed on the basis of both the parameter identification and performance detection.

- Optimization Based on the Parameter Identification

Step 1 : Pole Assignment.

From the identification, the estimated plant parameters $\hat{a}_{i}(i=1-4), \hat{b}_{j}(j=1-4)$ are obtained, and the system is expressed as follows :

$$
x(k+1)=-\sum_{i=1}^{4} \hat{a}_{i} x(k-i+1)+\sum_{j=1}^{4} \hat{b}_{j} u(k-j+1)(6)
$$


or

$$
\hat{A} x=\hat{B} u
$$

where

$$
\begin{aligned}
& \hat{A}=1+\sum_{i=1}^{4} \hat{a}_{i} q^{-i} \\
& \hat{B}=\sum_{j=1}^{4} \hat{b}_{j} q^{-j}
\end{aligned}
$$

and $q^{-1}$ is the back shift operator.

The discrete PID algorithm is expressed as :

$$
\begin{aligned}
u & =\frac{c_{0}+c_{1} q^{-1}+c_{2} q^{-2}}{1-q^{-1}}\left(R_{c}-x\right) \\
& =\frac{C}{1-q^{-1}} R_{c}-\frac{C}{1-q^{-1}} x
\end{aligned}
$$

where

$$
\begin{aligned}
& c_{0}=-\left(K_{p}+K_{i} \cdot T / 2+K_{d} / T\right) \\
& c_{1}=K_{p}-K_{i} \cdot T / 2+2 K_{d} / T \\
& c_{2}=-K_{d} / T
\end{aligned}
$$

or

$$
\begin{aligned}
& K_{p}=\left(c_{1}-c_{0}+3 c_{2}\right) / 2 \\
& K_{i}=-\left(c_{0}+c_{1}+c_{2}\right) / T \\
& K_{d}=-c_{2} T
\end{aligned}
$$

$R_{c}$ is the frequency set point, $T$ is the sampling period. Substituting equation (10) into equation (7) gives

$$
\left(\hat{A}\left(1-q^{-1}\right)-\hat{B} C\right) x=\hat{B} \cdot C \cdot R_{c}
$$

Letting $A_{d}$ as a desirable characteristic equation deduced from pole assignment, the following equation is required :

$$
\hat{A}\left(1-q^{-1}\right)-\hat{B} C=A_{d}
$$

$c_{0}, c_{1}$ and $c_{2}$ can be calculated from equation (14), and then $K_{p}, K_{i}$ and $K_{d}$ can be obtained from equation (12). In this way, the solution is not unique.

Step 2: The pole assignment technique is based on linear system. However, the water turbine governing system contains many non-linear links such as generation rate constraint, gate opening limit, dead band, etc. It is, therefore, proposed that the control parameters obtained from the pole assignment be used as reference only. Taking these parameters as starting point, choose three values each for $K_{p}, K_{i}$ and $K_{d}$ as test band. Then, using the orthogonal test approach (Appendix II), the optimal parameters and corresponding indices are obtained. The indices relative to the new control parameters are compared with that stored in the data base for old parameters. Using proper criteria, the control parameters that give better performance are stored in the data base. In other words, the data base always contains the best parameters.

\section{- Optimization Based on the Performance Detection}

During operation, besides the identification, tests proceed with some special test signals in order to optimize the control parameters. Until now, in the water turbine governing field, the parameters under no-load condition are selected with a lot of tests with human interference ; and the parameters under loaded condition are determined either with the parameters under no-load condition or with experimental formulae. In the proposed control strategy, tests are regularly conducted under different conditions. The orthogonal test approach is adopted for the parameter optimization because of its advantage of minimum number of tests [6]. Selecting an appropriate test signal for different conditions, and given a test band of each control parameter on the basis of previous information in the data base, the optimal parameters and corresponding indices are obtained. Then comparing the new indices with that in the data base, if the new indices are better, the parameters in the data base would be replaced by the new control parameters.

The above two optimization approaches are complementary. The common criterion for the parameter renewal is the performance appraisal. With the help of the two approaches, the control parameters are constantly self-improving.

\section{Test Signal Processing}

In order to identify plant parameters and to improve control structure and parameters, different test signals are stored in the data base. This unit is used to determine when and what type of signal is needed, and where should the signal be sent.

The white noise is used for identification excitation signal, and put on the governor output. In the proposed control strategy, the plant is identified at certain times, and the white noise is put into service only at these times.

The step change signal in frequency set point is mainly used for determining the optimal control parameters under no-load condition. It can also be used for loaded condition. As for the orthogonal test approach, a sequence of step change signals is stored in the data base. It will be sent to the controller under test conditions.

The step signal in gate opening set point is also a sequence of step changes. It is used for improving the parameters of gate opening tracking system.

The test signal processing branch would manage these signals. One of them would be put into service at appropriate time and place.

\section{Management Unit}

This unit manages the functioning of the above three units under specific rules.

\section{Results}

A number of simulation studies have been conducted. They show that the proposed control strategy is more rational and advantageous than the conventional governor. Results of a few studies are given below.

\section{Study of Control Parameter Self-Improvement}

Using the approach described in the preceding section, the control parameter self-improvement process is shown in Table VI and figure 9 under $1 \%$ step change in frequency set point.

The original values of control parameters stored in the data base are : $K_{p}=8.00, K_{i}=2.22, K_{d}=4.00$; and the corres- 


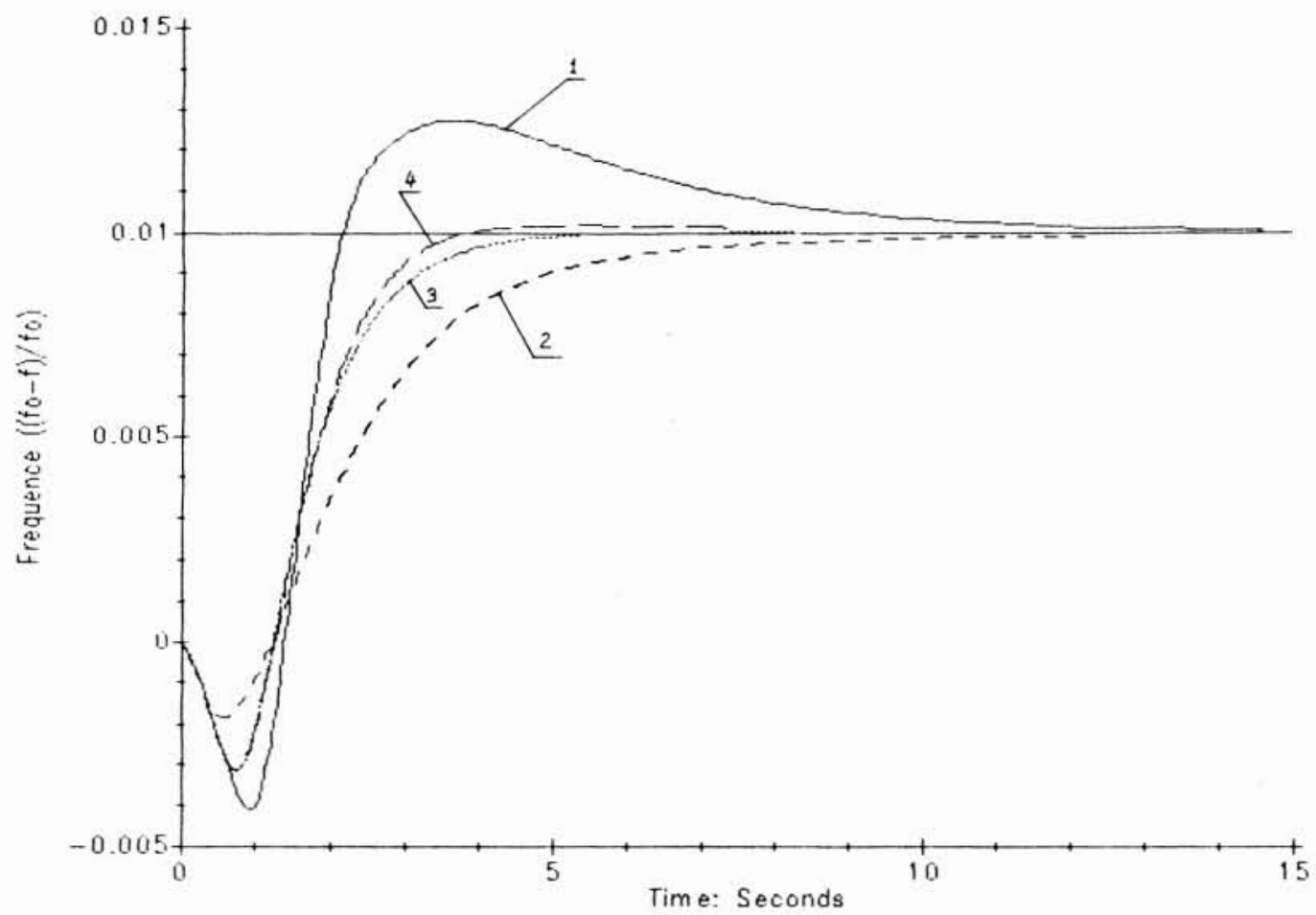

9. Control parameters self-improvement.

ponding indices are : $M_{p}=0.27, T_{s}=10.68, J=13.38$. After optimization tests, a new group of control parameters are found: $K_{p}=6.31, K_{i}=1.06, K_{d}=3.06$, and $M_{p}=0.0175$, $T_{\mathrm{s}}=3.44 \mathrm{~s}, J=3.615$. Compared with the original parameters, the new parameters are better, so they would replace the original ones in the data base.

\section{Study on Plant Structure Variation}

Figure /II and // show frequency response under plant structure variation. A $10 \%$ step change in load occurs at $t=0$, and a $1 \%$ step change in frequency set point occurs at $t=20 \mathrm{~s}$. In these two cases, the system has different closedloop transfer functions and different structures.

Table VI. - Control Parameter Self-Improvement

\begin{tabular}{|c|c|c|c|c|c|c|}
\hline \multirow{2}{*}{ Study } & \multicolumn{3}{|c|}{ Control Parameter } & \multicolumn{3}{|c|}{ Indices } \\
\cline { 2 - 7 } & $K_{r}$ & $K_{i}$ & $K_{d}$ & $T_{s}$ & $M_{r}$ & \\
\hline 1 & 8.00 & 2.22 & 4.00 & 10.68 & 0.27 & 13.38 \\
\hline 2 & 4.10 & 0.69 & 1.93 & 8.28 & 0 & 8.28 \\
\hline 3 & 6.37 & 1.06 & 3.36 & 4.32 & 0.0011 & 4.331 \\
\hline 4 & 6.31 & 1.06 & 3.06 & 3.44 & 0.0175 & 3.615 \\
\hline$* J=10 M_{p}+T_{s *}$
\end{tabular}

The curve 1 in figure 10 shows the frequency response with the constant optimal parameters $\left(K_{p}=9.59, \quad K_{i}=3.65\right.$, $\left.K_{d}=4.61\right)$ relative to a $10 \%$ step change in load.

The curve 2 shows the frequency response with the constant optimal parameters $\left(K_{p}=6.31, K_{i}=1.06, K_{d}=3.06\right)$ relative to $1 \%$ step change in frequency set point.

Frequency response with the proposed control strategy is shown in figure 11 . Detecting a $10 \%$ step change in load and other necessary information at $t=0$, an appropriate control structure and corresponding parameters $\left(K_{p}=9.59, K_{i}=\right.$ $\left.3.65, K_{d}=4.61\right)$ are selected ; and at $t=20 \mathrm{~s}$, on the basis of the detection and intelligent processing, other corresponding parameters $\left(K_{p}=6.31, K_{i}=1.06, K_{d}=3.06\right)$ that correspond to $1 \%$ step change in frequency set point are adopted. Comparing figure 11 with figure 10 , it is obvious that the proposed control strategy is much better.

\section{Conclusions}

- Combining some ideas from artificial intelligence, adaptive control and variable structure control, an intelligent selfimproving control strategy with both variable structure and parameters is proposed and developed. The connection of the proposed control strategy with multiprocessor-based system will open a new way for the water turbine governing system, probably also for other industrial process control. 


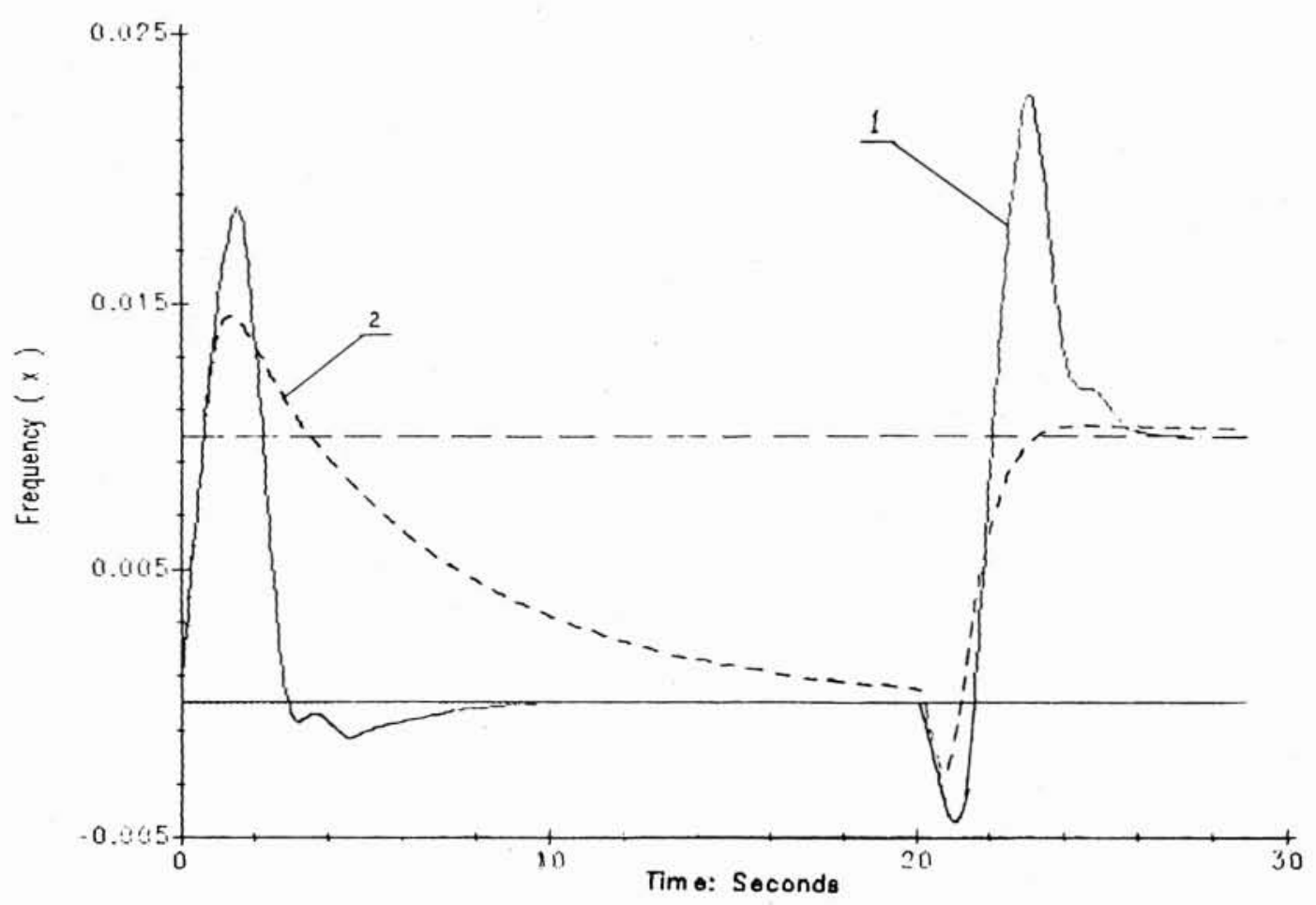

10. Frequency response for constant parameters.

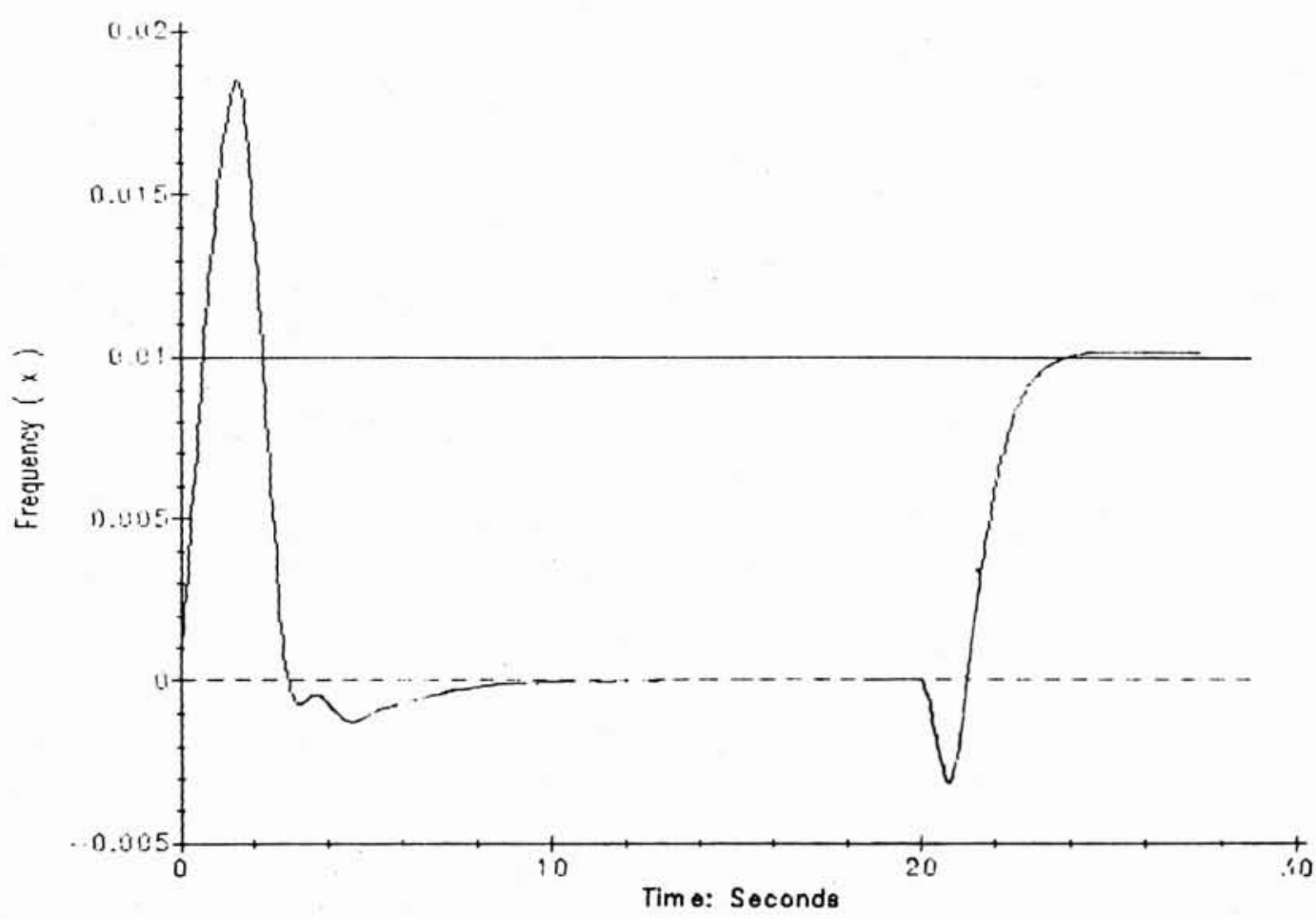

11. Frequency response with the proposed control strategy. 
- The proposed intelligent self-improving control strategy synthesizes a priori knowledge and experience, running identification/optimization information as well as analyzing and inferential capacity. In other words, the human knowledge accumulated in both theoretical and practical areas, frequent experiment and computation and artificial intelligence are organically connected. This control strategy makes the system to improve the performance.

- The selection of control structure depends on plant structure, operating point and state on the basis of plant structure detection, plant parameter identification and performance detection.
- Parameter identification is not the starting point of the control determination in each sampling period as is more common, but is a source for improving the knowledge bank contents.

- The multiprocessor-based system is obligatory for realizing the proposed control strategy, because the conventional analog systems are not able to accomplish the complex, intelligent self-improving control algorithm. The proposed hardware configuration is based on an already proven multimicroprocessor-based governor [1].

\section{Appendix I}

\section{Modeling of water turbine governing system}

The speed governing system with single-penstock/single-Francis turbine is shown in figure 12.

The mathematical models of each component and the system are given below. All physical variables in this appendix are relative deviations [7].

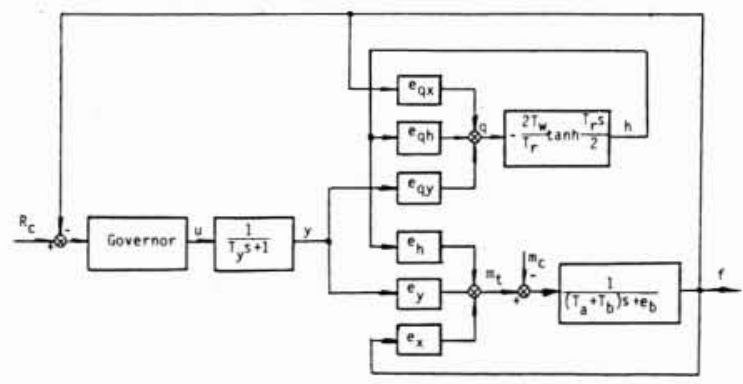

12. Speed governing system.

\section{Turbine}

In the neighbourhood of certain operating point. the linearized model of Francis turbine can be expressed as :

$$
\begin{aligned}
q & =e_{q y} y+e_{q h} h+e_{q x} x \\
m_{t} & =e_{y} y+e_{h} h+e_{x} x
\end{aligned}
$$

where $q$ is flow rate, $m_{f}$ is torque of turbine, $y$ is gate opening, $h$ is head, and $x$ is frequency.
The six transmission coefficients are

$$
\begin{aligned}
e_{q y}=\partial q / \partial y, & e_{q h}=\partial q / \partial h, & e_{q x}=\partial q / \partial x \\
e_{y}=\partial m_{t} / \partial y, & e_{h}=\partial m_{t} / \partial h, & e_{x}=\partial m_{t} / \partial x
\end{aligned}
$$

\section{Penstock}

The general expression of penstock taking account of elastic water hammer is a hyperbolic tangent function :

$$
\begin{aligned}
h / q & =-\frac{2 T_{w}}{T_{r}} \tanh \frac{T_{r s}}{2} \\
& =-\frac{2 T_{w s}}{T_{r}} \frac{e^{T_{r s} / 2}-e^{-T_{r s} / 2}}{e^{T_{r s} / 2}+e^{-T_{r s} / 2}}
\end{aligned}
$$

where $T_{w}$ is the water inertia time constant, $T$, is the penstock reflection time, $s$ is Laplace operator.

Equation (18) can be realized with pure delay in simulation. However, while $T_{r}$ is small, $e^{T_{r s} / 2}$ and $e^{-T_{r s} / 2}$ can be developed in series. Retaining only the first two terms for both the numerator and denominator, equation (18) simplifies to :

$$
\frac{h}{q}=-\frac{T_{w}}{T_{r}} \cdot \frac{T_{r s}+T_{r}^{3} s^{3} / 24}{1+T_{r}^{2} s^{2} / 8}
$$

Equation (19) can be expressed with a set of linear differential equations :

$$
\begin{aligned}
\dot{q} & =-24 q_{2} / T_{r}-3 h / T_{w} \\
\dot{q}_{2} & =q / T_{r}-q_{3} / T_{r} \\
\dot{q}_{3} & =-h / T_{w}
\end{aligned}
$$

where $q_{2}$ and $q_{3}$ are auxiliary variables. 


\section{Dynamic Equation of Generator Taking Account of} Load Characteristic

$$
\frac{x}{m_{t}-m_{c}}=\frac{1}{\left(T_{a}+T_{b}\right) s+e_{b}}
$$

where $T_{a}$ is unit inertia time constant, $T_{b}$ is the load inertia time constant, $e_{b}$ is the network load characteristic coefficient, $m_{c}$ is the load torque.

\section{Servomechanism}

Neglecting small time constants, the servomechanism can be expressed with a first order equation :

$$
y / u=1 /\left(T_{y} s+1\right)
$$

where $u$ is the control, $T_{y}$ is the servomotor response time.

\section{State Equation of Plant}

From equations (15), (16), (20) and (22), the following state and output equations can be obtained:

$$
\begin{gathered}
\dot{X}=A_{c} X+B_{c} u+F_{c} m_{c} \\
Y=C X
\end{gathered}
$$

where

$$
\begin{aligned}
& X^{T}=\left[x, q, q_{2}, q_{3}, y\right] \\
& A_{c} \text { is the system matrix } \\
B_{c}^{T}= & {[0,0,0,0,1 / T y] } \\
F_{c}^{T}= & {\left[-1 /\left(T_{a}+T_{b}\right), 0,0,0,0\right] } \\
C= & {[1,0,0,0,0] }
\end{aligned}
$$

Usually, $T_{y}$ is small relative to $T_{w}$ and $T_{a}$, so the $T_{y}$ can be neglected, and the model of plant can be simplifiec to :

$$
\begin{gathered}
\dot{X}^{\prime}=A_{c}^{\prime} X^{\prime}+B_{c}^{\prime} u+F_{c}^{\prime} m_{c} \\
Y=C X^{\prime}
\end{gathered}
$$

where

$$
X^{\prime T}=\left[x, q, q_{2}, q_{3}\right]
$$

The continuous state equation (25) can be transformed tc difference equation with a precise method [14] as follows :

$$
\begin{aligned}
x(k+1)=-\sum_{i=1}^{4} a_{i} x(k-i & +1)+ \\
& +\sum_{j=1}^{4} b_{j}(k-j+1)+e(k)
\end{aligned}
$$

where $a_{i}(i=1-4)$ and $b_{j}(j=1-4)$ are discrete plant par ameters, $k$ is the number of sampling period, i.e. the time and $e(k)$ is non-measurable disturbance or noise.

\section{Appendix 2 \\ Orthogonal test approach}

Orthogonal test [6] is an optimization approach based on the orthogonal table. It is suitable for multifactor and multiindex test with mutual effect between different factors and random errors. On the basis of orthogonality, the tests are well-distributed and comparable, and the optimal parameters are found by minimum test number. For the water turbine governing system, an orthogonal table can be established as shown in Table VII.

There are four factors: $K_{p}, K_{i}, K_{d}, B_{p}$ (permanent speed droop). Each factor contains three levels (values). Usually, 81 tests are necessary. But the orthogonal test approach needs 9 tests only.

\section{Algorithm :}

1. Conduct 9 tests according to Table VII, and obtain the corresponding indices $J_{k}(k=1-9)$.

2. Calculate the level-sum $K_{i}^{(j)}$ and level-average $k_{i}^{(j)}$ : where $i$ is level number, $j$ is factor number, e.g.

$$
\begin{array}{ll}
K_{1}^{(1)}=J_{1}+J_{2}+J_{3} & k_{1}^{(1)}=K_{1}^{(1)} / 3 \\
K_{2}^{(1)}=J_{4}+J_{5}+J_{6} & k_{2}^{(1)}=K_{2}^{(1)} / 3 \\
K_{3}^{(1)}=J_{7}+J_{8}+J_{9} & k_{3}^{(1)}=K_{3}^{(1)} / 3 \\
K_{3}^{(2)}=J_{3}+J_{6}+J_{9} & k_{3}^{(2)}=K_{3}^{(2)} / 3
\end{array}
$$


Table VII. - Orthogonal Table.

\begin{tabular}{|c|c|c|c|c|c|}
\hline $\begin{array}{l}\text { Factors } \\
\text { Test No. }\end{array}$ & $K_{p}$ & $K_{i}$ & $K_{d}$ & $B_{p}$ & Index \\
\hline 1 & 1 & 1 & 1 & 1 & $J 1$ \\
\hline 2 & 1 & 2 & 2 & 2 & $J 2$ \\
\hline 3 & 1 & 3 & 3 & 3 & $J 3$ \\
\hline 4 & 2 & 1 & 2 & 3 & $J 4$ \\
\hline 5 & 2 & 2 & 3 & 1 & J5 \\
\hline 6 & 2 & 3 & 1 & 2 & $J 6$ \\
\hline 7 & 3 & 1 & 3 & 2 & 17 \\
\hline 8 & 3 & 2 & 1 & 3 & $J 8$ \\
\hline 9 & 3 & 3 & 2 & 1 & $J 9$ \\
\hline$K_{1}$ & $K_{1}^{(1)}$ & $K_{1}^{(2)}$ & $K_{1}^{(3)}$ & $K_{1}^{(4)}$ & \\
\hline$K_{2}$ & $K_{2}^{(1)}$ & $K_{2}^{(2)}$ & $K_{2}^{(3)}$ & $K_{2}^{(4)}$ & \\
\hline$K_{3}$ & $K_{3}^{(1)}$ & $K_{3}^{(2)}$ & $K_{3}^{(3)}$ & $K_{3}^{(4)}$ & \\
\hline$k_{1}$ & $k_{1}^{(1)}$ & $k_{1}^{(2)}$ & $k_{1}^{(3)}$ & $k_{1}^{(4)}$ & \\
\hline$k_{2}$ & $k_{2}^{(1)}$ & $k_{2}^{(2)}$ & $k_{2}^{(3)}$ & $k_{2}^{(4)}$ & \\
\hline$k_{3}$ & $k_{3}^{(1)}$ & $k_{3}^{(2)}$ & $k_{3}^{(3)}$ & $k_{3}^{(4)}$ & \\
\hline$R$ & $R^{(1)}$ & $R^{(2)}$ & $R^{(3)}$ & $R^{(4)}$ & \\
\hline
\end{tabular}

3. Calculate the extreme difference for each factor, e.g.

$$
R^{(1)}=\max \left\{k_{1}^{(1)}, k_{2}^{(1)}, k_{3}^{(1)}\right\}-\left\{k_{1}^{(1)}, k_{2}^{(1)}, k_{3}^{(1)}\right\}
$$

4. Draw diagrams between each factor and index : taking the level $i$ as abscissa, $k_{i}$ as ordinate, draw broken-line graph.
If the slope of $k_{i}$ is greater, the corresponding factor has more influence. The optimal parameters corresponding to better index could then be selected.

\section{References}

[1] YE (Luqing), WEI (Shouping) and ZENG (Yuming). «Multiprocessor-based Fault Tolerant Adaptive Parameter-Optimized Governor for Water Turbine ». Proceedings, Mini and Microcomputers and Their Applications, pp. 57-62, 06/1985, Sant-Feliu, Spain.

[2] BADR (M. A. L.), Hope (G. S.) and MALIK (O. P.). « A SelfTuning PID Voltage Regulator for synchronous Generator ». Can. Elec. Eng. J. Vol. 8, No. 1, 1983, pp. 18-27.

[3] MALIK (O. P.), KumAR (Ashok) and Hope (G. S.). «A Load Frequency Control Algorithm Based on a Generalized Approach ", IEEE Trans. on Power Systems, Vol. 3(2), pp. 375-382, 1988.

[4] YE (Luqing), WEI (Shouping) et al. « Microprocessor-based Adaptive Governor with Variable PID Parameters for a Hydroelectric Generating Unit». Mini and Microcomputers and Their Applications, pp. 241-244, 06/1984, Bari, Italy.

[5] YE (Luqing) and WEI (Shouping). «An Adaptive PID-Parameter-Optimized Regulator and Its Application to Microprocessorbased Water Turbine Governor", Proceedings of the Second SinoJapanese Symposium on Fluid Machinery, 10/1987, Xian, China.

[6] WEI (Shouping). «Orthogonal Test Approach and Parameter Optimization " (in Chinese), Hydroelectric Apparatus, No. 3, 1983.

[7] YE (Luqing). « Model Reference Multivariable Optimal Control and Its Realization with a Microprocessor ». Mini and Microcomputers and Their Application, pp. 237-240, 06/1984, Bari, Italy.

[8] Astrom (K. J.) and Wittenmark (B.). «On Self Tuning Regulator", Automatica, Vol. 9, pp. 185-199, 1973.

[9] LANDAU (I. D.). "Adaptive Control. The Model Reference Approach ", Marcel, 1979.

[10] Narendra (Kumpati S.), Monopolı (Richard V.). «Application of Adaptive Control », Academic Press, 1980.

[11] EMEL'yanov (S. V.). " Theory of Variable Structure System » (in Russian), Nauka, Moscow, 1971.

[12] ITKIS (U.). "Control System of Variable Structure ", Keter Publishing House, 1976.

[13] Sage (A. P.) and Melsa (J. A.). "System Identification ", Academic Press, New York, 1971.

[14] FoulARD (C.) et al. «Commande et régulation par calculateur numérique », Editions Eyrolles, 1987. 


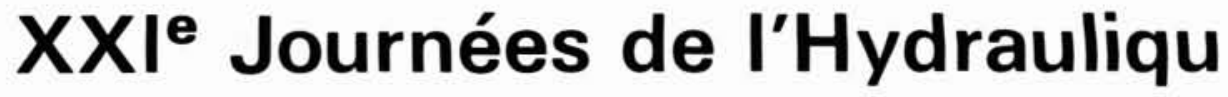 Sophia Antipolis, Valbonn 29 - 30 - 31 Janvier 199}

\section{Les eaux souterraines et la gestion des eaux Progrès, Quantité, Qualité}

\section{Appel à \\ communications}

\section{Rapporteurs \\ Généraux}

\section{Yves EMSELLEM,}

Ingénieur en Chef des Mines, Président de GÉOLAB, Valbonne.

\section{Michel DETAY}

Docteur es Sciences, Chargé de Mission, Centre de Formation International à la Gestion des Ressources en Eau (C.E.F.I.G.R.E.), Valbonne

Ghislain de MARSILY,

Professeur à I'Université Paris VI.

\section{Jean MARGAT,}

Ingénieur Géologue, Chargé de Mission Eau, Bureau de Recherches Géologiques et Minières (B.R.G.M.), Orléans.
En 1960 les $\left.\mathrm{V}\right|^{\mathbf{e}}$ Journées de l'Hydraulique ont été consacrées une première fois à I'Hydraulique Souterraine. En trente ans, la compréhension de l'intégration des eaux souterraines dans le cycle de l'eau, à toutes échelles, aussi bien que les techniques de leur étude et l'art de les exploiter ou de les protéger ont beaucoup progressé. La science des eaux souterraines, l'hydrogéologie, est entrée maintenant à part entière dans les sciences exactes aux côtés des autres branches de l'hydrologie et de l'hydraulique, sans rien céder de son appartenance aux sciences de la Terre, ni négliger l'approche naturaliste des complexités... De même, la maîtrise des eaux souterraines s'est incorporée pleinement au monde de l'hydrotechnique.

De nombreuses possibilités d'échanges entre chercheurs et ingénieurs ont été régulièrement offertes par diverses réunions et colloques, et des sujets impliquant l'eau souterraine ont été souvent inscrits aux programmes de diverses manifestations scientifiques ou techniques à champ tantôt plus large, tantôt plus sectoriel en France comme au plan international, notamment à l'initiative de la S.H.F. Pourtant l'image des eaux souterraines, la conception des ressources qu'elles offrent ou des problèmes qu'elles posent, la perception de la technicité des voies de leur connaissance, de leur mobilisation et de leur gestion, sont encore souvent en retrait dans bien des milieux scientifiques et professionnels - hors du cercle des spécialistes -, sans parler du grand public. Leur méconnaissance, la croyance qu'elles relèvent plutôt de l'e risme sont encore vivaces..

Les eaux souterraines n'en sont pas $n$ largement impliquées dans l'économi l'eau, voire de l'occupation et de l'utilis: du sous-sol en France et dans beaucou pays.

On se préoccupe davantage d'évalue possibilités de les exploiter plus, sans autant les "surexploiter ", d'estimer fragilité et leur sensibilité aux risques de lution, d'apprécier et de rendre effecti part qu'elles peuvent prendre dans l'am gement et la maîtrise des eaux en gén

Aussi a-t-il paru opportun d'offrir, au de la communauté scientifique et te que, la possibilité de faire le point sur de l'art en matière de connaissanc d'action sur les eaux souterraines, en consacrant les $\mathrm{XXI}^{\mathbf{\theta}}$ JOURNEES L'HYDRAULIQUE.

Cet appel à communications porte délit ment sur les aspects les plus novateur: connaissances - méthodes et résultats des techniques. Les sujets sont cla selon les catégories courantes : descrif des structures et de la compréhension phénomènes à toutes échelles, opéra de mobilisation, de prévention ou de res ration, procédures de gestion et des in ments d'aide aux décisions avec une or ture finale sur des réflexions anticipatr

P. CAZEN

Président du Comité Techr de la Société Hydrotechnique de $\mathrm{Fr}$ 